First publ. in: Journal of Membrane Biology 168 (1999), pp. 221-228

\title{
Ion Selectivity of the Cytoplasmic Binding Sites of the Na,K-ATPase: I. Sodium Binding is Associated with a Conformational Rearrangement
}

\author{
A. Schneeberger, H.-J. Apell \\ Department of Biology, University of Konstanz, Fach M635, D-78457 Konstanz, Germany
}

Received: 8 October 1998/Revised: 29 December 1998

\begin{abstract}
To investigate $\mathrm{Na}^{+}$binding to the ion-binding sites presented on the cytoplasmic side of the $\mathrm{Na}, \mathrm{K}$ ATPase, equilibrium $\mathrm{Na}^{+}$-titration experiments were performed using two fluorescent dyes, $\mathrm{RH} 421^{1}$ and FITC, to detect protein-specific actions. Fluorescence changes upon addition of $\mathrm{Na}^{+}$in the presence of various $\mathrm{Mg}^{2+}$ concentrations were similar and could be fitted with a Hill function. The half-saturating concentrations and Hill coefficients determined were almost identical. As RH421 responds to binding of a $\mathrm{Na}^{+}$ion to the third neutral site whereas FITC monitors conformational changes in the ATP-binding site or its environment, this result implies that electrogenic binding of the third $\mathrm{Na}^{+}$ ion is the trigger for a structural rearrangement of the ATP-binding moiety. This enables enzyme phosphorylation, which is accompanied by a fast occlusion of the $\mathrm{Na}^{+}$ions and followed by the conformational transition $\mathrm{E}_{1} / \mathrm{E}_{2}$ of the protein. The coordinated action both at the ion and the nucleotide binding sites allows for the first time a detailed formulation of the mechanism of enzyme phosphorylation that occurs only when three $\mathrm{Na}^{+}$ions are bound.
\end{abstract}

Key words: Na,K-ATPase - Cytoplasmic ion binding - Electrochromic fluorescent dye - FITC - Ion transport - Energy transduction mechanism

\section{Introduction}

The Na,K-ATPase is an integral plasma membrane protein of (virtually) all animal cells that employs the free enthalpy derived from the hydrolysis of ATP to actively transport $\mathrm{Na}^{+}$and $\mathrm{K}^{+}$ions against their electrochemical

Correspondence to: H.-J. Apell potential gradients. Under physiological conditions three $\mathrm{Na}^{+}$ions are moved out of the cell in exchange for two $\mathrm{K}^{+}$ions that are transported into the cytoplasm per molecule ATP hydrolyzed [11]. To perform this task the enzyme goes through a cycle of conformational transitions, phosphorylation and dephosphorylation steps and ion binding, occlusion, and release reactions $[7,12,19]$. From a mechanistic point of view several concepts have been formulated [22] that proved to be very useful not only to explain experiments but even to predict the behavior of an investigated system. So several functional and structural properties of the Na,K-ATPase could be unraveled, such as the presence of a phosphorylation site and its location [19], the existence of occluded states [7, $13,28]$, or the finding of an extracellular access channel $[9,30,37,41]$. A schematic representation of the pump cycle with regard to transport functions is given in Fig. 1. Since phosphorylation and cation binding sites are well separated from each other in the tertiary structure $[1,4$, $8,40]$, it is obvious that coupling of enzymatic and transport functions is indirect and requires conformational changes as a link between ATP-hydrolysis and the translocation event. Little is known about the nature of these conformational changes, their dimensions, the amino acids involved and their location in the protein structure. Fluorescence resonance energy transfer (FRET) between two covalently attached or reversibly bound fluorescent dyes has been used to measure distances between specific locations of the Na,K-ATPase [8] and thus estimate the size of conformational rearrangements [1, 23]. Single fluorescent labels such as FITC $^{1}$, IAF or BIPM have been utilized to monitor conformational changes by

\footnotetext{
${ }^{1}$ RH421: N-(4-sulfobutyl)-4-[4-(p-dipentylaminophenyl)butadienyl]pyridinium, inner salt; FITC: fluorescein 5-isothiocyanate (Isomer I), IAF: 5-iodoacetamidofluorescein, BIPM: N-[p-(2-benzimidazolyl)phenyl]maleimide.
} 


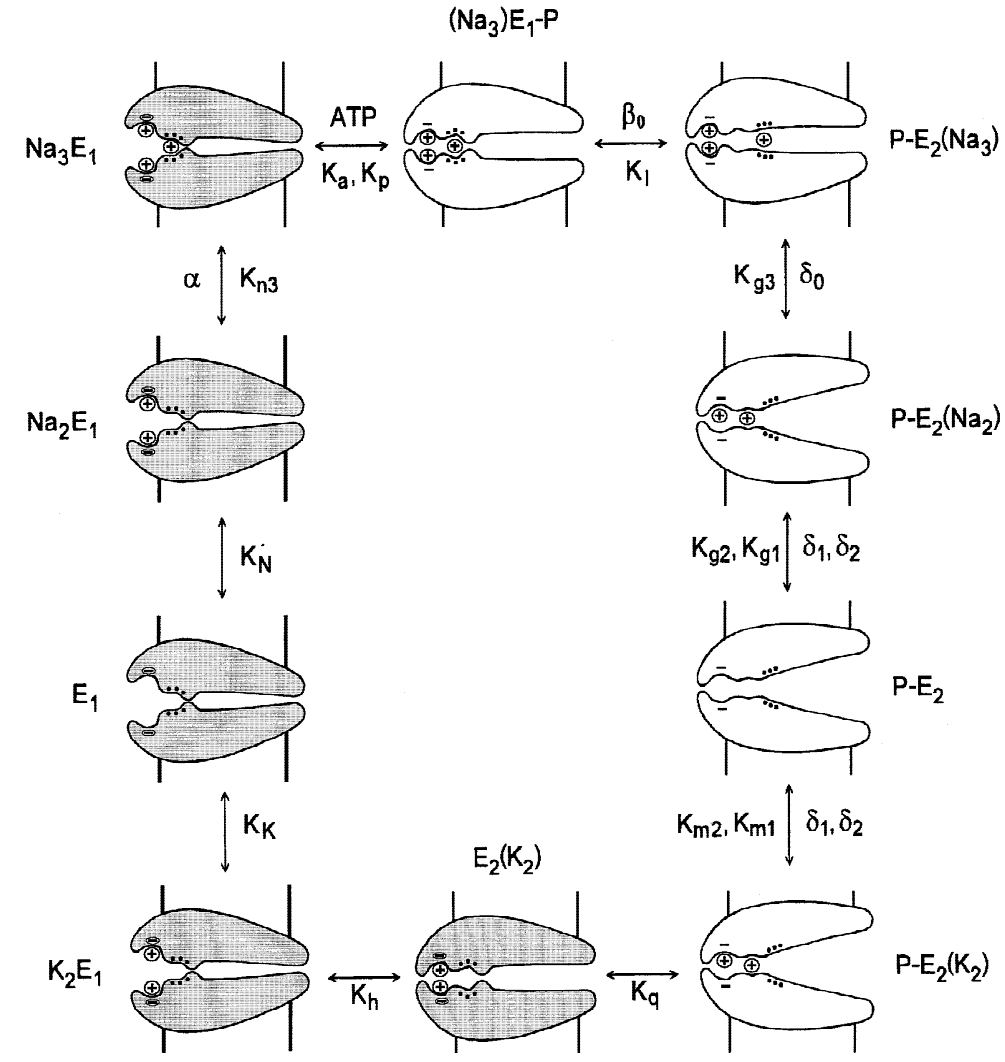

Fig. 1. Pump cycle of the Na,K-ATPase and its electrostatic properties developed from recent biophysical investigations [41]. The representation of the protein is meant only schematically and does not claim structural concepts. The equilibrium constants for the various reaction steps are given as $K_{x}(x=\mathrm{a}, \mathrm{p}, 1, \ldots$ as discussed in [41]). The Greek letters indicate electrogenic reaction steps in which net charge is moved through the protein perpendicular to the plain of the membrane. In conformation $\mathrm{E}_{1}$ of the pump 2 negatively charged binding sites are presented on the dielectric surface of the protein and one uncharged, $\mathrm{Na}^{+}$-specific site is placed within the protein dielectric. In conformation $\mathrm{E}_{2}$ all binding sites are accessible only through an access 'channel' which has a dielectric depth depending on the occupation of the binding sites. The hatched states of the enzyme in this figure are accessible in the absence of ATP and inorganic phosphate $\mathrm{P}_{i}$, and the transition between these are subject of this presentation. responding to the change in protein micro-environment $[15,16,21,26,31,35,38]$. Fluorescent dyes that do not bind covalently to the pump but reside in the lipid phase of membrane fragments containing Na,K-ATPase in high density have been applied to get information on transport properties of the pump [6, 20, 29, 37]. Particularly those steps of the transport cycle that involve the movement of charges can be studied very successfully by means of potential sensitive dyes. Using the electrochromic styryl dye RH421 various partial reactions of the pump cycle have been investigated and characterized with respect to their electrogenicity or electroneutrality $[3,17,36]$. In part I of this paper we combine experiments with FITC and RH421 and provide evidence that electrogenic binding of the third $\mathrm{Na}^{+}$ion at the cytoplasmic face is accompanied by a conformational rearrangement reported by FITC that structurally alters the nucleotide binding moiety and thus allows the transfer of energy-rich phosphate to the pump. In part II we will present experimental studies of the competition between $\mathrm{Na}^{+}$and a variety of inorganic and organic cations that imply that (i) two of the three cytoplasmic ion binding sites are accessible to all ions tested, and that (ii) the third binding site is perfectly restricted to $\mathrm{Na}^{+}$and can not bind any other ion.

\section{Materials and Methods}

Sodium dodecylsulfate (SDS) was obtained from Pierce Chemical. Phosphoenolpyruvate, pyruvate kinase, lactate dehydrogenase, NADH and ATP (disodium salt, special quality) were from Boehringer, Mannheim. The fluorescent dyes RH421 and FITC were from Molecular Probes, Eugene, OR. Dye purity was checked by thin-layer chromatography. All other reagents were the highest grade commercially available.

$\mathrm{Na}, \mathrm{K}$-ATPase was prepared from the outer medulla of rabbit kidneys in the form of open membrane fragments using procedure $\mathrm{C}$ of Jørgensen [18]. Protein concentration was assessed by the Lowry method, using bovine serum albumin as a standard. Specific ATPase activity was determined by the pyruvate kinase/lactate dehydrogenase assay [34]. The specific activity was in the range of 1900 to $2000 \mu \mathrm{M}$ $\mathrm{P}_{i}$ per $\mathrm{mg}$ protein and $\mathrm{hr}$ at $37^{\circ} \mathrm{C}$.

FITC labeling was performed according to the procedure of Karlish [21]: To remove sucrose and adjust the $\mathrm{pH}$ the enzyme was centrifuged in a Beckman airfuge at 30 Psi $(140,000 \times g)$ for $15 \mathrm{~min}$, washed, and resuspended in buffer containing $100 \mathrm{~mm}$ TRIS, $2 \mathrm{mM}$ EDTA, pH 9.2 to a final concentration of $1(-2) \mathrm{mg} / \mathrm{ml}$. FITC was added from a $500 \mu \mathrm{M}$ stock solution in dimethylformamide to a concentration of $10(-20) \mu \mathrm{M}$. Incubation at room temperature $\left(25^{\circ} \mathrm{C}\right)$ in the dark for $4 \mathrm{hr}$ provided quantitative coupling. Labeling was stopped by diluting the suspension 4- to 5-fold with an ice-cold solution containing $25 \mathrm{~mm}$ imidazole, $1 \mathrm{~mm}$ EDTA, $\mathrm{pH} 7.5$, and incubation for $1 \mathrm{hr}$ allowed dissociation of fluorescent by-products. To remove excess FITC the suspension was dialyzed at $4^{\circ} \mathrm{C}$ overnight against 1000 volumes of the imidazole buffer containing also $1 \mathrm{mg} / \mathrm{ml}$ bovine serum albumin, using a high speed Biotech Membrane (Spectra/Por ${ }^{\circledR}$ 2.1, $15,000 \mathrm{MWCO})$. Centrifugation in the airfuge at 30 Psi for $15 \mathrm{~min}$ and resuspension in buffer containing $25 \mathrm{~mm}$ histidine, $0.5 \mathrm{~mm}$ EDTA, $\mathrm{pH}$ 7.2 to a protein concentration of $2 \mathrm{mg} / \mathrm{ml}$ yielded quantitatively labeled enzyme with less than $1 \%$ ATPase activity.

Fluorescence measurements were carried out in a Perkin-Elmer LS 50B fluorescence spectrophotometer as described previously to de- 

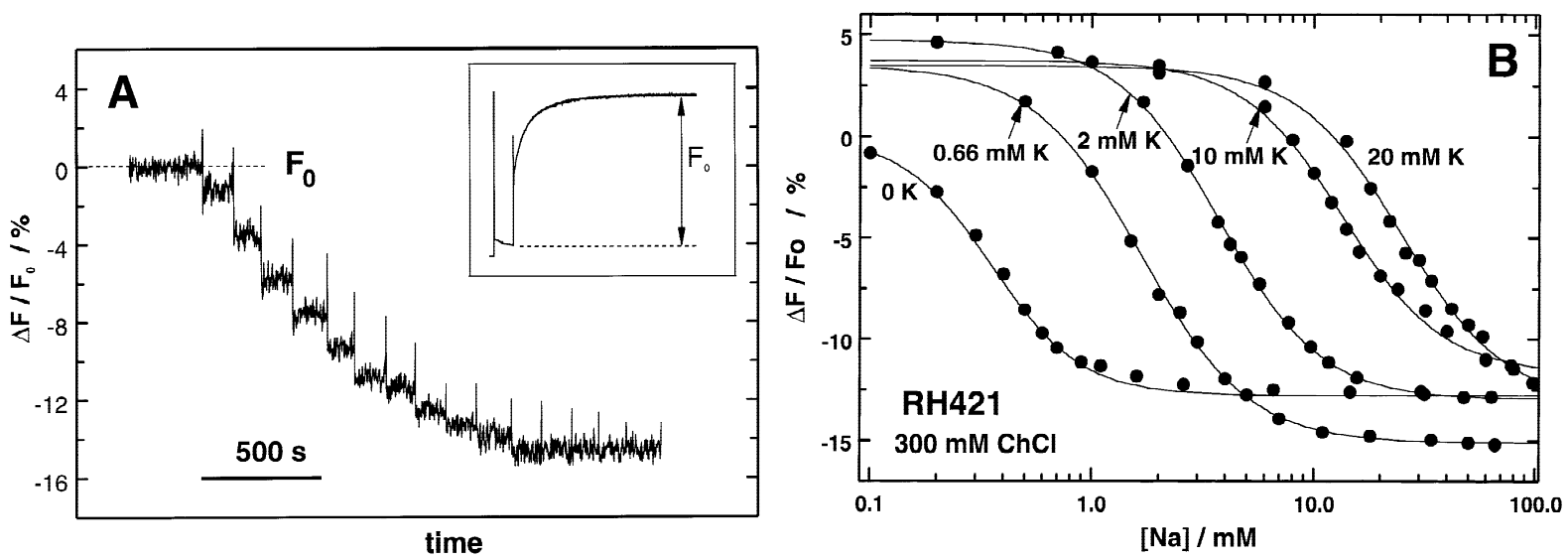

Fig. 2. $\mathrm{Na}^{+}$binding to the $\mathrm{Na}, \mathrm{K}-\mathrm{ATPa} e$ in conformation $\mathrm{E}_{1}$ studied by the styryl dye RH421. (A) Trace of the fluorescence intensity upon addition of aliquots of $\mathrm{NaCl}$ solutions to the standard buffer containing $25 \mathrm{~mm}$ histidine, $0.5 \mathrm{~mm}$ EDTA, pH 7.2, 300 mM choline chloride, $200 \mathrm{~nm}$ RH421 and $9 \mu \mathrm{g} / \mathrm{ml}$ of membrane fragments. The fluorescence decrease, $\Delta F / F_{0}$, was calculated relative to the level in the absence of $\mathrm{Na}^{+}$ions, $F_{0}$, as shown in the inset. $(B)$ Dependence of the relative fluorescence change on $\mathrm{Na}^{+}$concentration. Besides data without $\mathrm{K}^{+}$ions present (panel $A$ ), the results of titration experiments performed in the presence of the indicated concentrations of $\mathrm{K}^{+}$are included. The data could be fitted well with a Hill function (Eq. 1) as described in the text.

tect partial reactions of the ion-transport process [3, 37]. The thermostatically regulated cell holder was equipped with a magnetic stirrer. For experiments with RH421 the excitation wavelength was set to 580 $\mathrm{nm}$ and the emission wavelength to $650 \mathrm{~nm}$ (slit width $15 \mathrm{~nm}$ and 20 $\mathrm{nm}$, respectively). For experiments with FITC-labeled enzyme the excitation wavelength was set to $490 \mathrm{~nm}$ (slit width 5 or $10 \mathrm{~nm}$ ) and the emission wavelength to $520 \mathrm{~nm}$ (slit width $10 \mathrm{~nm}$ ). Equilibrium titration experiments were performed in buffer containing $25 \mathrm{~mm}$ histidine, 0 or 0.5 mm EDTA, pH 7.2, and $300 \mathrm{~mm}$ choline chloride. By the high ionic strength of the chosen buffer fluorophore artifacts were avoided and the pump was confined essentially to the initial state $\mathrm{E}_{1} .200 \mathrm{nM}$ $\mathrm{RH} 421$ (in the case of RH experiments) and 9-10 $\mu \mathrm{g} / \mathrm{ml}$ of membrane fragments containing FITC-labeled/unlabeled Na,K-ATPase were added to the thermostated cuvette and equilibrated until a stable fluorescence signal $F_{0}$ was obtained. As has been tested in a couple of experiments, both fluorescent labels could also be applied simultaneously and did not affect each other. Titrations were carried out by adding small aliquots of $\mathrm{NaCl} / \mathrm{KCl} / \mathrm{MgCl}_{2}$ solutions from various highly concentrated stocks until no further changes of fluorescence could be observed. To allow a comparison between different titration experiments relative fluorescence changes, $\Delta F / F_{0}=\left(F-F_{0}\right) / F_{0}$, were calculated (in \%) with respect to the initial fluorescence intensity $F_{0}$. (In case of RH421 experiments $F_{0}$ was diminished by the small fluorescence intensity of the dye dissolved in the buffer before addition of the membranes). Specific fluorescence levels could be assigned to defined states in the pump cycle of the Na,K-ATPase [17]. All experiments were performed at $16 \pm 0.5^{\circ} \mathrm{C}$.

\section{Results}

In conformation $\mathrm{E}_{1}$ the $\mathrm{Na}, \mathrm{K}-\mathrm{ATPase}$ presents three ion binding sites to the cytoplasm. When the electrochromic styryl dye RH421 is applied as a fluorescent probe electrogenic $\mathrm{Na}^{+}$binding is monitored leading to a fluorescence decrease due to the positive charge imported into the membrane $[3,37] . \mathrm{K}^{+}$binding can be detected only indirectly: $\mathrm{K}^{+}$ions compete with $\mathrm{Na}^{+}$ions and thus shift the half saturation constants for $\mathrm{Na}^{+}$binding to higher values with increasing $\mathrm{K}^{+}$concentrations. Since $\mathrm{K}^{+}$ binding is an electroneutral step it does not lead to a fluorescence change itself $[3,17]$. Over against this, $\mathrm{K}^{+}$ binding as measured by the FITC label leads to a large decrease in fluorescence intensity that reflects the conformational change $E_{1} \rightarrow E_{2}$. With this fluorescent probe $\mathrm{Na}^{+}$binding may be detected indirectly as the reversal of the $\mathrm{K}^{+}$-induced fluorescence drop. So, since the functional mechanisms of the two fluorophores are quite different, we wanted to prove whether results obtained by the two dyes were consistent.

\section{Equilibrium Titrations of $\mathrm{Na}^{+}$Binding TO THE UNPHOSPHORYLATED ENZYME WITH BOTH FLUORESCENT LABELS}

A series of equilibrium titration experiments was performed as described above. The fluorescence signal of RH421 was recorded (Fig. 2A) and the fluorescence changes relative to the level without $\mathrm{Na}^{+}$ions were calculated. The concentration dependence of the $\mathrm{Na}^{+}-$ induced fluorescence decrease is shown in Fig. 2B. Corresponding experiments were repeated in the presence of $\mathrm{K}^{+}$concentrations up to $20 \mathrm{~mm}$ (Fig. $2 B$ ). $\Delta F / F_{0}$ was calculated relative to the fluorescence intensity $F_{0}$ prior to the addition of $\mathrm{K}^{+}$or $\mathrm{Na}^{+}$. The initial supply of the indicated $\mathrm{K}^{+}$concentration redistributed the enzyme from state $\mathrm{E}_{1}$ into states $\mathrm{KE}_{1}, \mathrm{~K}_{2} \mathrm{E}_{1}$, and $\mathrm{E}_{2}\left(\mathrm{~K}_{2}\right)$. This transition caused only minor fluorescence increases $(\Delta F /$ $\left.F_{0}<5 \%\right)$. The subsequent addition of $\mathrm{Na}^{+}$led to the transition to state $\mathrm{Na}_{3} \mathrm{E}_{1}$ which resulted in a fluorescence decrease of approximately $18 \%$ and in a merging fluorescence level for all $\mathrm{K}^{+}$concentrations $( \pm 1 \%)$. The fluorescence changes were corrected for dilution effects. 

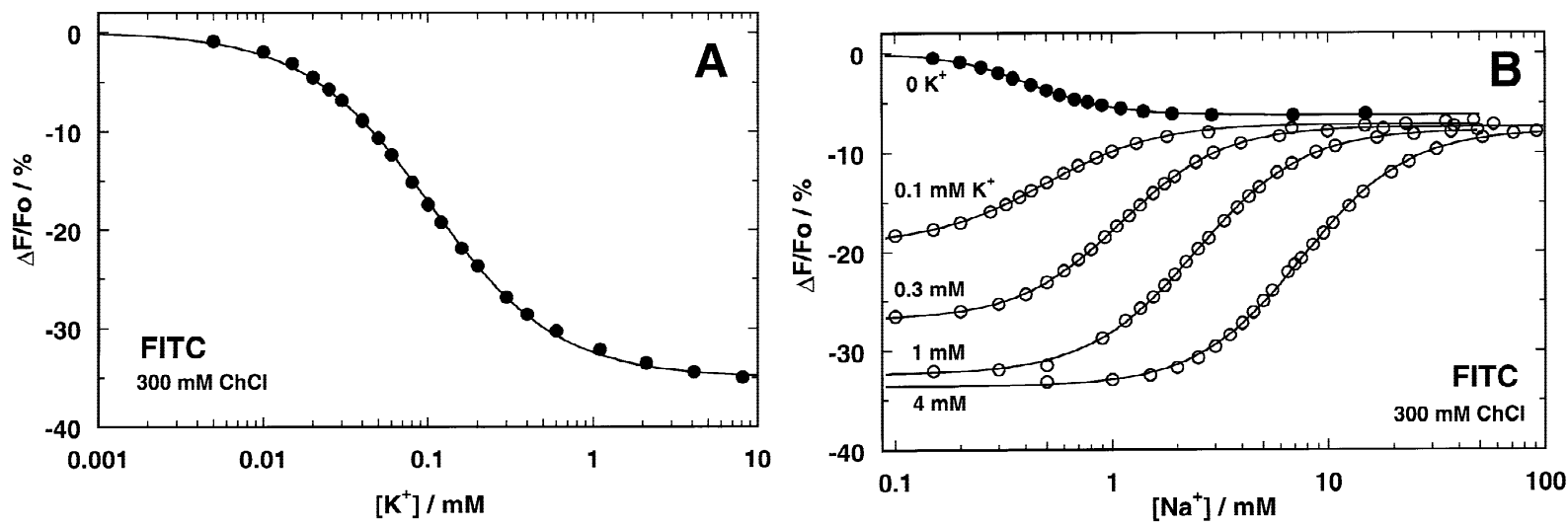

Fig. 3. $\mathrm{K}^{+}$and $\mathrm{Na}^{+}$binding to the $\mathrm{Na}, \mathrm{K}-\mathrm{ATPase}$ in conformation $\mathrm{E}_{1}$ investigated with protein labeled with FITC in standard buffer. (A) Addition of increasing amounts of $\mathrm{KCl}$ induced a fluorescence decrease of up to $35 \%$ with respect to the fluorescence intensity in the absence of $\mathrm{K}^{+}$. This change is caused by the transition $\mathrm{E}_{1} \rightarrow \mathrm{E}_{2}\left(\mathrm{~K}_{2}\right) .(B) \mathrm{Na}^{+}$-dependent changes of the FITC fluorescence. The reversal of the $\mathrm{K}^{+}$-induced decrease indicates the return of the ion pump into states of $\mathrm{E}_{1}$ (open circles). Independent of the initial $\mathrm{K}^{+}$concentration the fluorescence levels merged at high $\mathrm{Na}^{+}$concentrations at approximately $-7 \%$. This level was also reached when saturating $\mathrm{NaCl}$ was added in the absence of $\mathrm{K}^{+}$(solid circles).

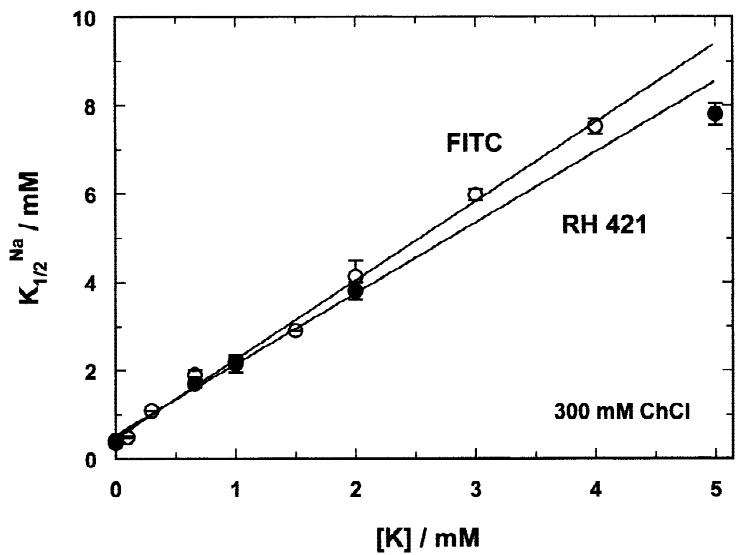

Fig. 4. Dependence of the half-saturating $\mathrm{Na}^{+}$concentrations, $K_{1 / 2}^{\mathrm{Na}}$, on the $\mathrm{K}^{+}$concentration present during the equilibrium titration experiments with both fluorescence labels, RH421 and FITC. The data were determined by analysis of experiments shown in Fig. $2 B$ and $3 B$ using the Hill function (Eq. 1).

The lines drawn in Fig. $2 B$ are fits of the Hill equation to the data,

$$
\frac{\Delta F}{F_{0}}=\left.\frac{\Delta F}{F_{0}}\right|_{\text {min }}+\left.\frac{\Delta F}{F_{0}}\right|_{\text {max }} \times \frac{1}{1+\left(K_{1 / 2}^{N a} /\left[\mathrm{Na}^{+}\right]\right)^{n_{H i l l}}} .
$$

Obviously, increasing $\mathrm{K}^{+}$concentrations shifted the halfsaturating concentration $K_{1 / 2}^{\mathrm{Na}}$ for $\mathrm{Na}^{+}$binding to higher values. The Hill coefficient $n_{\text {Hill }}$ was $1.90 \pm 0.06$, independent of the $\mathrm{K}^{+}$concentration.

When similar experiments were repeated with FITClabeled membrane fragments the $\mathrm{K}^{+}$-induced fluorescence change was much more pronounced as can be seen in Fig. 3A. Addition of saturating $\mathrm{K}^{+}$concentrations (>1
mM) led to a fluorescence drop of approximately $35 \%$. The lower fluorescence intensity level is attributed to state $\mathrm{E}_{2}\left(\mathrm{~K}_{2}\right)$. Fitting the Hill equation (Eq. 1) to the data yielded parameter values of $K_{1 / 2}^{K}=0.1 \mathrm{~mm}$ and $n_{\text {Hill }}=$ 1.1. These values are in good agreement with previously published results $[16,21]$. Addition of increasing amounts of $\mathrm{Na}^{+}$ions reversed the $\mathrm{K}^{+}$-induced fluorescence quench (Fig. $3 B$ ). All traces saturated at the same level of $\Delta F / F_{0}=-7.1( \pm 0.2) \%$ and not at the initial fluorescence level before addition of $\mathrm{K}^{+}$. To check whether this difference was caused by $\mathrm{Na}^{+}$binding $\mathrm{NaCl}$ was supplied in an additional experiment up to a concentration of $50 \mathrm{~mm}$ without prior addition of $\mathrm{K}^{+}$so that the $\mathrm{Na}^{+}$titration started from state $\mathrm{E}_{1}$. This titration resulted in a fluorescence drop reaching the same final level as observed in the titration experiments in the presence of $\mathrm{K}^{+}$(Fig. 3B). Again the lines are fits of the Hill equation (Eq. 1) to the data. For a comparison the halfsaturating concentrations of $\mathrm{Na}^{+}$binding, $K_{1 / 2}^{\mathrm{Na}}$, derived from the experiments with both methods (Figs. 2, 3) are depicted in Fig. 4 as a function of the $\mathrm{K}^{+}$concentration. Obviously, the values obtained are quite similar. The same is true for the Hill coefficient determined from the experiments with FITC-labeled enzyme, which was $n_{\text {Hill }}$ $=1.87 \pm 0.07$ independent of the $\mathrm{K}^{+}$concentration.

In addition, Fig. $3 B$ reveals that the sole addition of $\mathrm{Na}^{+}$ions to FITC-labeled Na,K-ATPase already confined to state $E_{1}$ resulted in a significant fluorescence change, too. Control experiments excluded that this fluorescence drop was due to the fluorophore responding to an increase in ionic strength (data not shown). In fact, raising the ionic strength from the standard concentration of $300 \mathrm{~mm}$ to $450 \mathrm{~mm}$ by adding choline chloride did not lead to a significant fluorescence change $(<2 \%)$. Moreover, titrating the $\mathrm{Na}^{+}$-only induced FITC-fluorescence change yielded a half-saturating constant $K_{1 / 2}^{N a}=0.42 \pm$ 

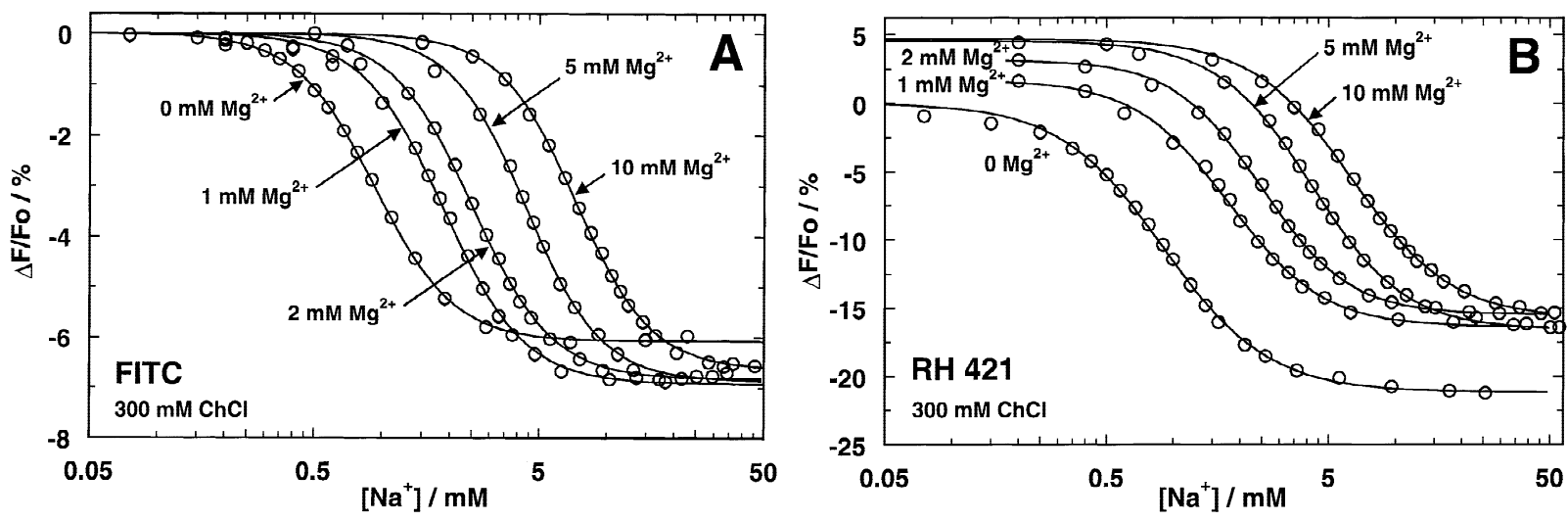

Fig. 5. $\mathrm{Na}^{+}$binding to the $\mathrm{Na}, \mathrm{K}-\mathrm{ATP}$ ase in conformation $\mathrm{E}_{1}$ in the presence of various $\mathrm{Mg}^{2+}$ concentrations studied by both fluorescence labels, $(A)$ FITC and $(B) \mathrm{RH} 421$, in standard buffer without EDTA. Increasing concentrations of $\mathrm{Mg}^{2+}$ shift the $\mathrm{Na}^{+}$-dependent fluorescence changes to higher $\mathrm{Na}^{+}$concentrations. The lines drawn through the data represent fits with the Hill function (Eq. 1) from which half-saturating concentrations $K_{1 / 2}^{N a}$ were derived.

$0.02 \mathrm{~mm}\left(\right.$ at $\left.0 \mathrm{~K}^{+}\right)$that is very similar to the $0.36 \pm 0.01$ mM determined by the RH421 method. To substantiate the assumption that this fluorescence decrease reflects $\mathrm{Na}^{+}$binding to state $\mathrm{E}_{1}$, titration experiments in the presence of various $\mathrm{Mg}^{2+}$ concentrations were performed. Figure $5 \mathrm{~A}$ shows the effect of $\mathrm{Mg}^{2+}$ on the $\mathrm{Na}^{+}$-induced fluorescence decrease of the FITC label. Increasing $\mathrm{Mg}^{2+}$ concentrations shifted the half-saturating concentration $K_{1 / 2}^{N a}$ to higher values indicating a decreasing apparent affinity for $\mathrm{Na}^{+}$with increasing concentration of the divalent cation. Correspondingly, $\mathrm{Na}^{+}$-titration experiments were performed under exactly the same conditions using the styryl dye RH421 instead (Fig. 5B). Figure 6 shows a comparison of the half-saturating concentrations derived by the two methods. Evidently, the two dyes change their fluorescence in the same way upon addition of $\mathrm{Na}^{+}$ions and the $K_{1 / 2}^{\mathrm{Na}}$ values derived by the use of the two fluorophores are identical within experimental error.

\section{Discussion}

During the last 10 years FITC has been effectively used to monitor cation-induced conformational changes of $\mathrm{Na}, \mathrm{K}-\mathrm{ATPase}$. Our equilibrium titrations using FITClabeled preparations from rabbit outer medulla proved that our enzyme binds $\mathrm{K}^{+}$ions with a $K_{1 / 2}^{K}$ of $0.1 \mathrm{~mm}$ (Fig. $3 A)$ in agreement with previously published data $[16$, 21]. The interesting new finding is that $\mathrm{Na}^{+}$binding to state $\mathrm{E}_{1}$ could be monitored by the FITC method (Fig. $3 B$ ) as well as by the RH421 method (Fig. $2 B$ ) and both led to comparable results (Fig. 4). Since excitation and emission wavelengths of both dyes are different, the effect on both labels could be measured with the same preparation. Control experiments showed that neither RH421 affected the measurement of cation binding as

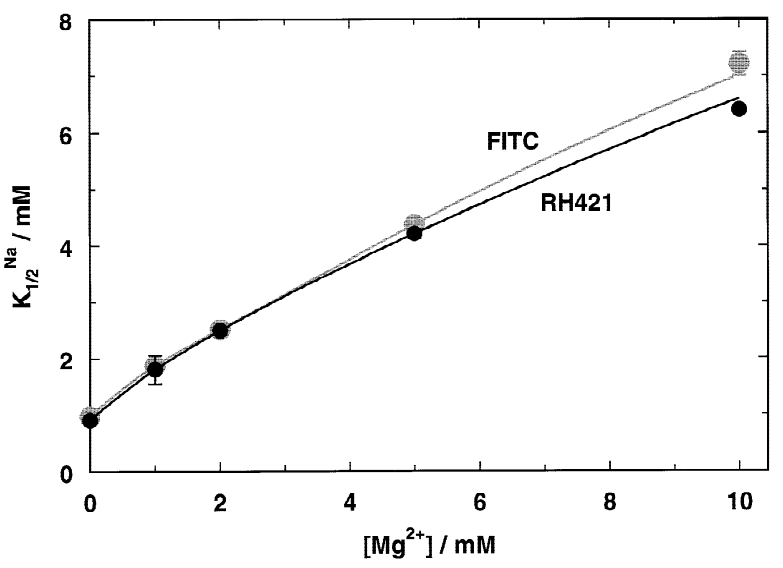

Fig. 6. Half-saturating concentrations $\mathrm{K}_{1 / 2}^{\mathrm{Na}}$ of $\mathrm{Na}^{+}$binding to the $\mathrm{Na}, \mathrm{K}-$ ATPase detected with both fluorescence labels, RH421 and FITC. The error bars are mostly within the size of the markers. The agreement of the results from both series of experiments indicate that they report the same ion-pump specific process. The almost linear increase of $K_{1 / 2}^{N a}$ may be explained by competitive binding of $\mathrm{Mg}^{2+}$ ions to the ion binding sites of the Na,K-ATPase.

probed by FITC nor altered FITC-labeling the cation affinities as probed by RH421 compared to non-labeled enzyme. These findings are in agreement with recent results using stopped-flow techniques [24]. The majority of previously published experiments with FITC have been explained on the basis of two distinguishable conformations, $E_{1}$ and $E_{2}$. In contrast to that, Hegvary and Jørgensen [16] were able to detect several states of fluorescein-labeled $\mathrm{Na}, \mathrm{K}-\mathrm{ATPase}$ by their corresponding fluorescence levels. Our labeled Na,K-ATPase preparation exhibited an additional fluorescence level, too, which was generated by $\mathrm{Na}^{+}$binding and had a slightly lower fluorescence intensity $(-7 \pm 0.2 \%)$ than that of conformation $\mathrm{E}_{1}$ (contrary to [16] where a small en- 
hancement of fluorescence intensity is reported upon $\mathrm{Na}^{+}$ binding).

Although the $\mathrm{Na}^{+}$-induced fluorescence change was small compared to that of the $\mathrm{E}_{1} \rightarrow \mathrm{E}_{2}$ transition it was significant and could be titrated leading to a half saturating concentration of $\mathrm{Na}^{+}$-binding that was very similar to the one determined by the RH421 method (Figs. 3B, $5 A$ ). Moreover, the concentration dependence of the interaction of $\mathrm{Mg}^{2+}$ ions with the ion-binding sites and the resulting reduction of the apparent affinities of $\mathrm{Na}^{+}$binding was reported in the same way by both dyes and produced identical results within experimental error (Fig. 6). When $\mathrm{Na}^{+}$binding was reversed by addition of saturating $\mathrm{K}^{+}$concentrations $\mathrm{RH} 421$ and FITC changed their fluorescence also correspondingly (data not shown).

A possible explanation of the concurrent behavior of the two fluorescent labels has to be based on their functional properties. RH421 is known to detect specifically the electrogenic binding of a $\mathrm{Na}^{+}$ion to the uncharged binding site, which is assumed to be the third to be filled $[17,32]$. The concomitant fluorescence decrease, which reflects an uptake of positive charge in the protein dielectric, is restricted perfectly to $\mathrm{Na}^{+}$and could not be produced with any other cation (manuscript in preparation). On the other hand FITC binds predominantly to Lys-501 within the ATP-binding site of Na,K-ATPase in the large cytoplasmic loop of the protein between the transmembrane domains M4 and M5 [5]. The mechanism of the fluorescein label is based on the $\mathrm{pH}$ sensitivity of its chromophore which changes its absorption and fluorescence spectra upon small alterations of $\mathrm{pH}$ of its local environment. Even minor structural rearrangements in the neighborhood of the label, like movements of polar side chains of amino acids in the scale of a few Angstroms, may cause variations of the local $\mathrm{pH}$ that are reported in turn by the dye.

Obviously binding of $\mathrm{Na}^{+}$ions to their sites, which are formed by parts of the transmembrane segments of the $\alpha$ subunit of the protein $[4,33]$, affects the fluorescence of FITC which is bound in the ATP-binding site in the cytoplasmic part of the protein. Conformationdependent spatial rearrangements of the cytoplasmic part of the protein which contains the enzymatic apparatus of the ion pump have been observed by different techniques. Besides the well-established different tryptic digestion patterns between conformations $\mathrm{E}_{1}$ and $\mathrm{E}_{2}$ more detailed evidence for conformation-sensitive interactions between cytoplasmic domains were presented by Goldshleger and Karlish [14]. They showed by Fe-catalyzed cleavage of the $\alpha$ subunit of $\mathrm{Na}, \mathrm{K}-\mathrm{ATPase}$ that major and minor loops move apart during the $\mathrm{E}_{2} \rightarrow \mathrm{E}_{1}$ transition. Such a rearrangement of moieties could easily account for the major change of FITC fluorescence observed corresponding to this transition. Additional effects specific to the ATP-binding site have been reported recently by Gatto et al. [10]. They showed that $\mathrm{H}_{2}$ DIDScrosslinking between Lys-501 and Lys-480 occurs in the presence of $\mathrm{Na}^{+}$ions but is prevented by low concentrations of $\mathrm{K}^{+}$which are sufficient to maintain binding of at least one $\mathrm{K}^{+}$ion. This finding indicated that the distance between both lysines in the "Na-bound form", which we interpret as state $\mathrm{Na}_{3} \mathrm{E}_{1}$ of $\mathrm{Na}, \mathrm{K}-\mathrm{ATPase}$, has changed by several Angstroms compared to the " $\mathrm{K}^{+}$-bound form".

With our FITC-labeled Na,K-ATPase preparation we are able to discriminate between three groups of protein states: (1) $\mathrm{E}_{2}\left(\mathrm{~K}_{2}\right)$, (2) $\mathrm{K}_{2} \mathrm{E}_{1}, \mathrm{KE}_{1}, \mathrm{E}_{1}, \mathrm{NaE}_{1}, \mathrm{Na}_{2} \mathrm{E}_{1}$, and (3) $\mathrm{Na}_{3} \mathrm{E}_{1}$. This classification is a consequence of the two different reporter mechanisms of RH421 and FITC and the completely corresponding changes of their fluorescence upon addition of $\mathrm{Na}^{+}$. In terms of a mechanistic interpretation the observed effects suggest that binding of the third $\mathrm{Na}^{+}$ion to state $\mathrm{Na}_{2} \mathrm{E}_{1}$ of the ion pump induces a rearrangement of one or more transmembrane segments of the $\alpha$ subunit of the protein that is propagated to the cytoplasmic loop which forms the ATP binding moiety. A likely mediator of the signal transmission between the catalytic site and the cation binding sites might be the peptide segment intervening between Asp-371 and the PEGL motif present at the cytoplasmic end of the fourth transmembrane segment M4, which is highly conserved in Na,K-ATPase and other closely related P-type ATPases [39]. Other possible candidates are the also highly conserved junctional Region $\mathrm{J}$, the "hinge" region and the M5-M6 hairpin [25, 27].

On the basis of the observation that under almost all ionic conditions the stoichiometry of $3 \mathrm{Na}^{+} / 1 \mathrm{ATP}$ is maintained for active $\mathrm{Na}^{+}$transport by $\mathrm{Na}, \mathrm{K}$-ATPase we propose that under physiological conditions binding of the third $\mathrm{Na}^{+}$to its highly ion-selective site is the trigger mechanism that will move the phosphorylation site, Asp371 , into the right position to enable the transfer of the energy-rich $\gamma$-phosphate from enzyme-bound ATP to the protein. This model supports also the reasoning from previously published experiments on $\mathrm{Na}^{+}$binding to the $\mathrm{Na}$,K-ATPase performed with RH421 [32], which requests that two $\mathrm{Na}^{+}$ions have to occupy the negatively charged binding sites in state $\mathrm{E}_{1}$ before the third may be bound. A deviation from such a strict stoichiometry has been proposed only for extremely low cytoplasmic sodium concentrations in the case of inside-out red cell vesicles [2].

The existence of such a trigger mechanism has to be postulated on principal considerations, as it is necessary for the pump to make sure that the unique partial reaction which utilizes the free enthalpy provided by ATP is accomplished only if the physiologically required number of $\mathrm{Na}^{+}$ions are bound to the pump. Under physiological conditions the hydrolysis of ATP provides free enthalpy in the order of $55 \mathrm{~kJ} / \mathrm{mol}$ and the electrochemical work to transfer each $\mathrm{Na}^{+}$ion from the cytoplasm to the extra- 
cellular space is in the order of $12.5 \mathrm{~kJ} / \mathrm{mol}$ [22]. Therefore $\sim 23 \%$ of the energy available is spent for the transport of each $\mathrm{Na}^{+}$ion. To elude waste of energy it is crucial for the ion pump to maintain a fixed coupling ratio under physiological conditions.

The presented interpretation of the intriguingly corresponding data from RH421 and FITC experiments offers a straightforward explanation to the question of how the ion pump manages to become phosphorylated only in the event that three $\mathrm{Na}^{+}$ions are bound.

We thank Dr. Achim Linder for helpful discussion. This work was financially supported by the Deutsche Forschungsgemeinschaft (Sonderforschungsbereich 156).

\section{References}

1. Amler, E., Abbott, A., Ball, W.J. Jr. 1992. Structural dynamics and oligomeric interactions of $\mathrm{Na}^{+}, \mathrm{K}^{+}$-ATPase as monitored using fluorescence energy transfer. Biophys. J. 61:553-568

2. Blostein, R., Polvani, C. 1992. Altered stoichiometry of the Na,KATPase. Acta Physiol. Scand. 146:105-110

3. Bühler, R., Stürmer, W., Apell, H.-J., Läuger, P. 1991. Charge translocation by the Na,K-pump: I. Kinetics of local field changes studied by time-resolved fluorescence measurements. J. Membrane Biol. 121:141-161

4. Capasso, J.M., Hoving, S., Tal, D.M., Goldshleger, R., Karlish, S.J.D. 1992. Extensive digestion of $\mathrm{Na}^{+}, \mathrm{K}^{+}$-ATPase by specific and nonspecific proteases with preservation of cation occlusion sites. J. Biol. Chem. 267:1150-1158

5. Farley, R.A., Tran, C.M., Carilli, C.T., Hawke, D., Shively, J.E. 1984. The amino acid sequence of a fluorescein-labeled peptide from the active site of (Na,K)-ATPase. J. Biol. Chem. 259:95329535

6. Fedosova, N.U., Cornelius, F., Klodos, I. 1995. Fluorescent styryl dyes as probe for $\mathrm{Na}, \mathrm{K}-\mathrm{ATPase}$ reaction mechanism: Significance of the charge of the hydrophilic moiety of RH dyes. Biochemistry 34:16806-16814

7. Forbush, B., III. 1988. Occluded ions and Na,K-ATPase. In: $\mathrm{Na}^{+}, \mathrm{K}^{+}$-Pump. Part A: Molecular Aspects. J.C. Skou, J.G. Nørby, A.B. Maunsbach and M. Esmann, editors. pp. 229-248. A.R. Liss, New York

8. Fortes, P.A., Aguilar, R. 1988. Distances between 5-iodoacetamidofluorescein and the ATP and ouabain sites of $(\mathrm{Na}, \mathrm{K})$ ATPase determined by fluorescence energy transfer. In: $\mathrm{Na}^{+}, \mathrm{K}^{+}$Pump. Part A: Molecular Aspects. J.C. Skou, J.G. Nørby, A.B Maunsbach, M. Esmann, editors. pp. 197-204. A.R. Liss, New York

9. Gadsby, D.C., Rakowsky, R.F., De Weer, P. 1993. Extracellular access to the Na,K-pump: Pathway similar to ion channel. Science 260:100-103

10. Gatto, C., Lutsenko, S., Kaplan, J.H. 1997. Chemical modification with dihydro-4,4'-diisothiocyanostilbene-2,2'-disulfonate reveals the distance between $\mathrm{K}_{480}$ and $\mathrm{K}_{501}$ in the ATP-binding domain of the Na,K-ATPase. Arch. Biochem. Biophys. 340:90-100

11. Glynn, I.M. 1984. The electrogenic sodium pump. In: Electrogenic Transport: Fundamental Principles and Physiological Implications. M.P. Blaustein and M. Liebermann, editors. pp. 39-45. Raven Press, New York

12. Glynn, I.M. 1985. The $\mathrm{Na}^{+}, \mathrm{K}^{+}$-transporting adenosine triphospha- tase. In: The Enzymes of Biological Membranes (2nd ed.). A.N. Martonosi, editor. Vol. 3, pp. 35-114. Plenum, New York

13. Glynn, I.M., Richards, D.E. 1983. Existence and role of occludedion forms of Na,K-ATPase. Curr. Top. Membr. Transp. 19:625638

14. Goldshleger, R., Karlish, S.J.D. 1997. Fe-catalyzed cleavage of the $\alpha$ subunit of $\mathrm{Na} / \mathrm{K}$-ATPase: Evidence for conformation-sensitive interactions between cytoplasmic domains. Proc. Natl. Acad. Sci. USA 94:9596-9601

15. Grell, E., Warmuth, R., Lewitzki, E., Ruf, H. 1991. Precision titrations to determine affinity and stoichiometry of alkali, alkaline earth, and buffer cation binding to Na,K-ATPase. In: The Sodium Pump: Recent Developments. J.H. Kaplan, P. De Weer, editors. pp. 441-445. The Rockefeller University Press, New York

16. Hegyvary, C., Jorgensen, P.L. 1981. Conformational changes of renal sodium plus potassium ion-transport adenosine triphosphatase labeled with fluorescein. J. Biol. Chem. 256:6296-6303

17. Heyse, S., Wuddel, I., Apell, H.-J., Stürmer, W. 1994. Partial reactions of the Na,K-ATPase: determination of rate constants. $J$. Gen. Physiol. 104:197-240

18. Jørgensen, P.L. 1974. Isolation of $\left(\mathrm{Na}^{+}+\mathrm{K}^{+}\right)$-ATPase. Enzymol. 32:277-290

19. Jørgensen, P.L., Andersen, J.P. 1988. Structural basis for $E_{1}-E_{2}$ conformational transitions in $\mathrm{Na}, \mathrm{K}$-pump and Ca-pump proteins. $J$. Membrane Biol. 103:95-120

20. Kane, D.J., Grell, E. Bamberg, E., Clarke, R.J. 1998. Dephosphorylation kinetics of pig kidney $\mathrm{Na}^{+}, \mathrm{K}^{+}$-ATPase. Biochemistry 37:4581-4591

21. Karlish, S.J.D. 1980. Characterization of conformational changes in $(\mathrm{Na}, \mathrm{K})$ ATPase labeled with fluorescein in the active Site. $J$. Bioeng. Biomembr. 12:111-136

22. Läuger, P. 1991. Electrogenic ion pumps. Sinauer Associates, Sunderland, MA

23. Lin, S-H., Faller, L.D. 1996. Estimation of the distance change between cysteine- 457 and the nucleotide binding site when sodium pump changes conformation from $\mathrm{E}_{1}$ to $\mathrm{E}_{2}$ by fluorescence energy transfer measurements. Biochemistry 35:8419-8428

24. Lin, S-H., Smirnova, I.N., Kasho, V.N., Faller, L.D. 1997. Eosin, energy transfer, and RH421 report the same conformational change in sodium pump as fluorescein. Ann. N.Y. Acad. Sci. 834:442444

25. Lutsenko, S., Kaplan, J.H. 1995. Organization of P-type ATPases: Significance of structural diversity. Biochemistry 34:15607-15613

26. Mezele, M., Lewitzki, E., Ruf, H., Grell, E. 1988. Cation selectivity of membrane proteins. Ber. Bunsenges. Phys. Chem. 92:9981004

27. Møller, J.V., Juul, B., le Maire, M. 1995. Structural organization, ion transport, and energy transduction of P-type ATPases. Biochim. Biophys. Acta 1286:1-51

28. Post, R.L., Hegyvary, C., Kume, S. 1972. Activation by adenosine triphosphate in the phosphorylation kinetics of the sodium and potassium ion transport adenosine triphosphatase. J. Biol. Chem. 247:6530-6540

29. Pratap, P.R., Robinson, J.D., Steinberg, M.I. 1991. The reaction sequence of the $\mathrm{Na}^{+} / \mathrm{K}^{+}$-ATPase: rapid kinetic measurements distinguish between alternative schemes. Biochim. Biophys. Acta 1069:288-298

30. Rakowsky, R.F., Vasilets, L.A., LaTona, J., Schwarz, W. 1991. A negative slope in the current-voltage relationship of the $\mathrm{Na}^{+} / \mathrm{K}^{+}$ pump in Xenopus oocytes produced by reduction of external $\left[\mathrm{K}^{+}\right]$. J. Membrane Biol. 121:177-187

31. Rephaeli, A., Richards, D., Karlish, S.J.D. 1986. Conformational transitions in fluorescein-labeled $(\mathrm{Na}, \mathrm{K}) \mathrm{ATPase}$ reconstituted into phospholipid vesicles. J. Biol. Chem. 261:6248-6254 
32. Schulz, S., Apell, H.-J. 1995. Investigation of ion binding to the cytoplasmic binding sites of the Na,K-pump. Eur. Biophys. J. 23:413-421

33. Schwappach, B., Stürmer, W., Apell, H.-J., Karlish, S.J.D. 1994. Binding of sodium ions and cardiotonic steroids to native and selectively trypsinized $\mathrm{Na}, \mathrm{K}$ pump, detected by charge movements. J. Biol. Chem. 269:21620-21626

34. Schwartz, A.K., Nagano, M., Nakao, M., Lindenmayer, G.E., Allen, J.C. 1971. The sodium- and potassium-activated adenosinetriphosphatase system. Meth. Pharmacol. 1:361-388

35. Smirnova, I.N., Faller, L.D. 1993. Role of $\mathrm{Mg}^{2+}$ ions in the conformational change reported by fluorescein $5^{\prime}$-isothiocyanate modification of $\mathrm{Na}^{+}, \mathrm{K}^{+}$-ATPase. Biochemistry 32:5967-5977

36. Stürmer, W., Apell, H.-J. 1992. Fluorescence study on cardiac glycoside binding to the Na,K-pump. Ouabain binding is associated with movement of electrical charge. FEBS Lett. 300:1-4

37. Stürmer, W., Bühler, R., Apell, H.-J., Läuger, P. 1991. Charge translocation by the Na,K-pump: II. Ion binding and release at the extracellular face. J. Membrane Biol. 121:163-176

38. Taniguchi, K., Tosa, H., Suzuki, K., Kamo, Y. 1988. Microenvironment of two different extrinsic fluorescence probes in $\mathrm{Na}^{+}, \mathrm{K}^{+}$ATPase changes out of phase during sequential appearance of reaction intermediates. J. Biol. Chem. 263:12943-12947

39. Vilsen, B. 1997. Leucine 332 at the boundary between the fourth transmembrane segment in the cytoplasmic domain of $\mathrm{Na}^{+}, \mathrm{K}^{+}-$ ATPase plays a pivotal role in the ion translocating conformational changes. Biochemistry 36:13312-13324

40. Vilsen, B., Ramlov, D., Andersen, J.P. 1997. Functional consequences of mutations in the transmembrane core region for cation translocation and energy transduction in the $\mathrm{Na}^{+}, \mathrm{K}^{+}$-ATPase and the SR Ca ${ }^{2+}$-ATPase. Ann. N.Y. Acad. Sci. 834:297-309

41. Wuddel, I., Apell, H.-J. 1995. Electrogenicity of the sodium transport pathway in the Na,K-ATPase probed by charge-pulse experiments. Biophys. J. 69:909-921 